\title{
Periodontal Muscle Training can Strength the Periodontal Support, Fit Your Teeth
}

\section{Nima Sabzchamanara*}

Department of Therapeutic Dentistry, National Medical University, Bogomolets, Kiev, Ukraine

*Corresponding author: Nima Sabzchamanara, Department of Therapeutic Dentistry, National Medical University, Bogomolets, Kiev, Ukraine, Tel: +00380637022522; E-mail: nima.sch@icloud.com

Received date: November 30, 2016; Accepted date: January 02, 2017; Published date: January 09, 2017

Copyright: ( 2017 Sabzchamanara N. This is an open-access article distributed under the terms of the Creative Commons Attribution License, which permits unrestricted use, distribution, and reproduction in any medium, provided the original author and source are credited.

Citation: Sabzchamanara N (2017) Periodontal Muscle Training can Strength the Periodontal Support, Fit Your Teeth. Dentistry 7: 406. doi: 10.4172/2161-1122.1000406

\begin{abstract}
Previous research on periodontal structure and function has shown a significant relationship between periodontal tissue and teeth. This study assessed dentist's beliefs about the relative efficacy of the health of periodontal tissue. A total of 505 patients in general practice were asked to respond to a list of 25 obligatory nourishments for a child while going to have the first teeth, for its effectiveness in dealing with patient's periodontal health especially include chewing hard food. They were also asked to select the three effective nutrition for periodontal tissue. The indicts of patient perceived importance of the periodontal health were derived and each compared with actual effectiveness as determined from a sample of 250 patients.
\end{abstract}

Although the majority of patient's 18 of 25 nutritions as being very effective, there was no significant association with patient perceived nourishment effectiveness and actual effectiveness. The implications for patient training are discussed.

\section{Introduction}

What to do to have esthetically and functionally prevention method for further gum and periodontal diseases, which could be less aggressive and conservative, cheap and home treating methods. In case one cares about his body's physique, also he can care about the Gum structure as well [1].

\section{Materials and Methods}

Bundels attached to teeth and their disattachments provoke further injuries. Lets take a look at these bundles, if we peal away alveolar septa and papillae \& marginal part, we can see the budles (periodontal ligament), which is composed of bundles of connective tissues fiber that anchor the teeth within the jaw. Each bundle is attached to cementum covering the root of the tooth. The other end is embedded in bony tooth sockets (alveolar socket). These bundles of fibers allow the tooth to withstand the forces of biting and chewing [2].
Endomysium, the connective tissue sheaths that surround each skeletal muscle fiber separating the muscle cells from one another. It also contains capillary nerves and lymphatics. As an illustration, Organization of skeletal tissues, Intact skeletal muscle. Biceps brachi are attached to bones through tendons-connective tissue. The entire muscle is surrounded by connective tissue called epimysium. The muscle is organized into bundles called premysium. Each fasciculus contains many individual fibers surrounded by connective tissue called Endomysium [3].

In some muscles there might only be relatively few fibers such as in muscle of the eye in which these are only 10 of fibers. In some of the bigger muscles in the body there may be thousands of fibers, for instance, there can be up to 400000 fibers in the bicep muscle in front of the arm. Each of these fibers is surrounded by sheaths of fibrous tissue membrane or fascia called Endomysium (endo-means within).

\section{Results}

As within skeletal growth, the muscles in the body also grow at irregular rates. The enlargement of muscles (hypertrophy) makes them thicker but muscle fibers can also get longer. With certain types of training and genetics, muscle mass can change.

According to the aging of muscular system, one reason is reducing the strength and power of the muscles, therefore, by training the endomysiums within the periodontal ligament with special trainings as well as eating hard foods and chewing them we can train them exactly like fitness club.

\section{References}

1. Anatomy and Physiology A\&P McGraw-Hill Glossary.

2. Plowman SA, Smith DL (2013) Exercise Physiology for Health Fitness and Performance. Lippincott Williams \& Wilkins.

3. Coulson M (2013) The Complete Guide to Personal Training. Bloomsbury Publishing. 